\title{
A política de expansão e financiamento da pós-graduação: as diretrizes do PNPG (2011-2020) e PNE (2014-2024)
}

The political expansion and financing of the post-graduation: the guidelines of the PNPG (2011-2020) and PNE (2014-2024)

La política de expansión y financiación de posgrado: las directrices del PGNP (2011-2020) y PNE (2014-2024)

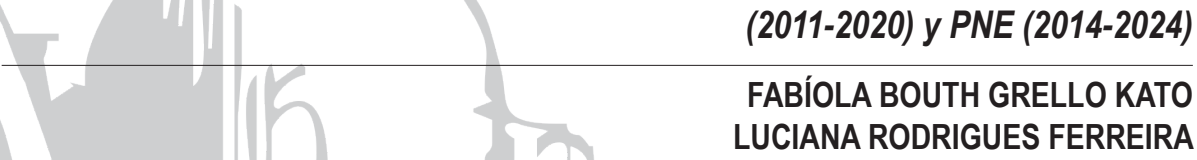

Resumo: $\mathrm{O}$ artigo versa sobre a atual política de expansão e de financiamento da pós-graduação por meio da análise do Plano Nacional de Pós-Graduação - PNPG (2011-2020) e da meta 14 do novo Plano Nacional de Educação - PNE (20142024). No contexto de uma pesquisa Qualitativa, sob recursos documentais, analisam-se o atual PNPG, o PNE, e o ordenamento jurídico que regulamentam as atividades de C,T\&I brasileira, além de dados obtidos por meio do Geocapes, dentre outras fontes. As análises indicam que a política de indução da expansão e do financiamento da pós-graduação brasileira reposicionou o papel do Estado como agente indutor dessa atual etapa de expansão, seja pela via do uso do fundo público, seja pela regulamentação jurídica recente.

Palavras-chave: PNE; Pós-graduação; PNPG.

Abstract: This paper analyzes the current post-graduation expansion and financing policy through the analysis of PNPG (2011-2020) and the goal 14 of the new PNE (2014-2024). In the context of a qualitative research under documental resources, it analyzes the current PNPG, PNE and the legal order that regulates the Brazilian C.T\&I activities, in addition to data obtained by means of Geocapes, among other sources. The analysis indicate that the expansion induction policy and the Brazilian post-graduation financing repositioned the role of the Estate as the inductor of this current expansion, either by the use of public funds, either by the recent legal regulation.

Keywords: PNE, post-graduation, PNPG.

Resumen: El artículo analiza la actual política de expansión y financiación de Posgrado a través del análisis del Plan Nacional de Posgrado -PGNP (2011-2020) y de la meta 14 del nuevo Plan Nacional de Educación - PNE (2014-2024). En el contexto de una investigación Cualitativa, bajo recursos documentales, se analiza el PGNP actual, el PNE, y el ordenamiento jurídico que regulan las actividades de C, T \& I brasileña, además de datos obtenidos por medio del Geocapes, entre otras fuentes. Los análisis indican que la política de la inducción de la expansión 
y de financiación del posgrado brasileño reposicionó el papel del Estado como agente inductor de esta actual fase de expansión, sea por medio de la utilización de fondos públicos, sea por la reglamentación jurídica reciente.

Palabras clave: PNE; Posgrado; PGNP.

\section{INTRODUÇÃO}

A identificação ideológica entre Estado e o público, e a relação entre público e privado faz da análise das políticas públicas educacionais um cenário complexo, especialmente quando se busca relacionar com o financiamento, no qual o movimento do Estado transita entre o mercantil e o estatal. Fatos cotidianos nos mostram esse movimento: um exemplo foi a chamada "Governo quer privatizar a oferta da educação na instituição pública", publicada pelo Sindicato Nacional dos Docentes das Instituições de Ensino Superior (ANDES-SN), em 02 de março de 2016, matéria na qual se analisou a Proposta de Emenda à Constituição (PEC) no 395/2014, que, uma vez aprovada, permitirá às universidades públicas a cobrança de mensalidades pelos cursos de extensão e pós-graduação lato sensu.

Ainda conforme a matéria do ANDES-SN, a PEC coloca em xeque o princípio constitucional da gratuidade prevista no inciso IV do artigo 206 da Constituição Federal de 1988, que dispõe: "O ensino será ministrado com base nos seguintes princípios: [...] IV - gratuidade do ensino público em estabelecimentos oficiais" (BRASIL, 1988), alterando o financiamento das atividades de cursos de especialização oferecidas pelas Instituições de Ensino Superior (IES) públicas.

Tal alteração constitucional significaria, com efeito, munição para uma ampla política de ataque à oferta pública de Educação Superior, ampliando a mercantilização da produção e oferta do conhecimento em Instituições públicas e a desobrigação do Estado com seu financiamento. Para o diretor do ANDES-SN, a aprovação dessa PEC permitiria, a priori, a cobrança de mensalidades em cursos de pós-graduação lato sensu, mas, em outro momento, redundaria em cobrança para outros cursos oferecidos nas IES públicas

\footnotetext{
A possibilidade de cobrança de taxas e mensalidades, em um segundo momento, de cursos regulares de graduação, mestrado e doutorado [...] descaracterizaria a função social das universidades públicas. Essa PEC faz parte de uma política mais geral, que é de desresponsabilização do Estado na área da educação pública. Já vivemos um cenário de crescimento do setor privado na Educação Superior, e a medida amplia esse processo de privatização e mercantilização. (ANDES-SN, 2016).
}

Outro destaque refere-se a aprovação da Lei no 13.243/2016, mais conhecida como Novo Marco Legal da Ciência, Tecnologia e Inovação que cumprirá, de 
acordo com o discurso da então presidenta Dilma Rousseff, uma nova agenda para esse setor, permitindo a integração entre agentes públicos e privados que compõem o sistema de Ciência, Tecnologia e Inovação, o que possibilita a ampliação da relação de cooperação entre a comunidade científica, o governo e o setor empresarial.

De acordo com o exposto na lei e com a avaliação da então presidenta,

\begin{abstract}
Isso vai possibilitar a justa remuneração das universidades públicas e dos centros de pesquisa, propiciando mais recursos para investimento e para novos avanços na qualidade da educação e da produção de conhecimento. Permitirá, portanto, transformar a inovação bem sucedida em patrimônio de toda a sociedade brasileira. Temos, portanto, muitos motivos para celebrar o novo Código Nacional de Ciência, Tecnologia e Inovação. Abrimos sem dúvida uma nova etapa na cooperação entre universidades, institutos de pesquisa, Estado e empresas, cujos resultados serão mais oportunidades para nossa população e mais competitividade para o nosso País. (ROUSSEFF, 2016).
\end{abstract}

A tramitação da PEC no 395/14 e a aprovação do novo marco regulatório para a ciência, tecnologia e inovação representado aqui pela Lei no 13.243/16 (BRASIL, 2016) traduzem a atualização de um projeto nacional que vem, a conta-gotas, institucionalizando-se desde a década de 1990, em direção à mercantilização da Educação Superior, caracterizado, sobretudo, pela penetração de mecanismos e valores de mercado sobre a gestão, financiamento, avaliação e produção de conhecimento em nossas IES públicas.

Essas alterações exigem reposicionamento da Instituição universidade, pois, de um lado, ciência e tecnologia ampliam seu papel de destaque no âmbito das forças produtivas do capital a partir do aumento da taxa de lucro por meio da extração de mais valia relativa, alterando a inserção de técnicos e cientistas na sociedade uma vez que se tornam agentes econômicos diretos (CHAUÍ, 1999). De outro, as alterações na base produtiva do capital passam a impor novas formas de sua valorização do capital, novos arranjos produtivos e um novo papel do Estado e de uso do fundo público. (PAULANI, 2008)

Por sua vez, o Estado, por meio de ordenamento jurídico-estratégico, implementa ações de curto, médio e longo prazo que reorientam as instituições republicanas e o fundo público quanto a suas finalidades e aplicações, a exemplo dos planejamentos educacionais para a pós-graduação - Plano Nacional de PósGraduação (PNPG) 2011-2020 e o Plano Nacional de Educação (PNE) 20142024/Meta 14.

Compreender, portanto, a complexidade histórica das transformações politicoeconômicas do Brasil e suas relações com a internacionalização da produção e com o trabalho, especialmente o trabalho intelectual desenvolvido 
por pesquisadores, agora mais orientado pelas relações econômicas, tornou-se fundamental para entender a influência do capital nas relações de financiamento da pesquisa no Brasil, especialmente citados a Coordenação de Aperfeiçoamento de Pessoal de Nível Superior (CAPES), o Conselho Nacional de desenvolvimento Científico e Tecnológico (CNPq), a Financiadora de Estudos e Projetos (FINEP), os Institutos Nacionais de Ciência e Tecnologia (INCT) e as agências estaduais de financiamento a pesquisa.

Nessa perspectiva, o objetivo deste artigo é o de contribuir para os estudos sobre a atual política nacional de expansão e financiamento da pós-graduação, por meio da análise do Plano Nacional de Pós-Graduação 2011-2020 e do Plano Nacional de Educação 2014-2024) e das políticas públicas que vêm concretizando tal planejamento, vista a centralidade da educação para o desenvolvimento econômico e produtivo do país. Ou seja, é apresentar a atualidade desse amplo corpo de reformas institucionais que reposicionam o papel do Estado, o financiamento das políticas públicas sociais, com destaque para o financiamento das universidades públicas.

\section{REFORMA NO ESTADO E NOVO PAPEL DO FUNDO PÚBLICO}

Segundo Oliveira (1999), ideologicamente, a chamada privatização do público, ou falência do Estado, sustenta-se pela falsa consciência da desnecessidade do público, o que constitui a "pedra de toque" para sua privatização. Em outras palavras, a privatização do público ganha força na chamada falência do Estado, pelo mecanismo da dívida pública interna em que, na aparência, é o privado e o setor financeiro/bancário que emprestam ao Estado, logo, desse ponto de vista, o Estado só se sustentaria como uma extensão do próprio privado.

Observa-se, entretanto, que está por detrás dessa aparência o oposto: é a riqueza pública, sob a forma do fundo público que sustenta a reprodutibilidade da ampliação da riqueza do capital privado. Esta seria, portanto, conforme Oliveira (1999), a forma moderna de sustentação da crise do capital, que já demonstrou em tempos anteriores, a exemplo da crise de 1929, que o capital simplesmente se desvaloriza.

É essa ideologia que tem sustentado a reforma do Estado Brasileiro, expressamente declarada, no plano político, na publicação do Plano Diretor de Reformas do Aparelho do Estado e, ainda, no plano jurídico, por uma série de alterações legais que vêm promovendo a condição brasileira de plataforma de valorização do capital financeiro. 
Esta adesão do Brasil ao capitalismo de predominância financeira ${ }^{1}$ impôs ao país uma série de ajustes estruturais, sobretudo jurídicos, com sua máxima expressão no Plano Diretor de reforma do Aparelho do Estado, publicado em 1995, cujo objetivo central seria a transformação do país numa economia juridicamente atrativa para novas formas de valorização de capital, e baseada, sobretudo, na desregulamentação trabalhista, gestão monetária da economia e na atração de Investimento Externo Direto (IED). (SILVA JÚNIOR et al., 2012)

Dito de outro modo, o novo modelo econômico que predomina com o chamado fim do Estado de Bem-estar social reposiciona a função do Estado e da gestão de seu fundo público. Se em período anterior, por exemplo, as políticas sociais eram, com destaque para o pleno emprego e para as políticas trabalhistas, meta de política econômica, exercendo esse fundo público mediado pelo Estado, papel preponderante na reprodução da classe trabalhadora por meio de políticas sociais, a partir da década de 1980, nos países de economia central, e da década de 1990 no Brasil, a ideologização da desnecessidade do público ganha destaque pelo fato de que há novas formas de utilização do fundo público sem necessariamente passar pela reprodução direta da classe trabalhadora. (OLIVEIRA, 1999; KATO, 2013)

A crise estrutural do capital da década de 1970, que teve como uma das principais características a diminuição das taxas de lucro, vão impor novas formas de valorização do capital, novos arranjos produtivos e um novo papel ao Estado e ao seu fundo público. É sob esse ponto de vista que, no Brasil, emerge um amplo servilismo financeiro, calcado num estado de emergência econômico, que impõe ao país, por seus representantes legais, a sobreposição da agenda econômica sobre os direitos sociais da grande maioria da população. (PAULANI, 2008)

Para Paulani (2008), a prioridade central do país na adesão ao capital financeiro passa a ser a preservação de garantias constitucionais aos credores econômicos. São esses os objetivos que vêm orientando, há quase duas décadas quaisquer políticas e reformas educacionais.

Várias foram as mudança implementadas nesta direção: securitização da dívida pública, ou seja, a internacionalização do mercado interno brasileiro de títulos públicos; a desregulamentação financeira expressa nas chamadas contas CC5, que nas palavras de Paulani (2008) seria a decretação da liberdade de envio

Esse novo processo de reorganização econômica e política da atual etapa do capitalismo é conhecido por "mundialização do capital", expressão cunhada por Chesnais (1996) para designar um movimento em que uma empresa forte num ramo industrial, descentraliza-se em diversas unidades por todo o mundo, em diversos países ou regiões, na busca de maiores vantagens produtivas: menores custos e maiores vantagens quanto a força de trabalho, matéria prima, leis trabalhistas, universidades a serviço das empresas. Aqui residiria, para Silva Júnior (2012), a diferença entre internacionalização e a mundialização da economia, uma vez que nesta nova etapa, o capital produtivo também se internacionaliza na forma de Investimento Externo Direto (IED). 
de recursos ao exterior, decretação esta absolutamente irregular do ponto de vista jurídico, mas justificada pela necessidade de modernização do mercado financeiro brasileiro, retirando os entraves que impediam a livre saída de recursos do país.

Podemos citar ainda: a decretação do Plano Real; a venda ao capital internacional de empresas públicas de setores estratégicos, como as do setor de energia elétrica e telecomunicações, a preços subavaliados pelo Estado, orientando a entrada de grupos predominantemente industriais no país; elevação das taxas básicas de juros; aprovação de emenda constitucional que aprovou a isenção de CPMF aos recursos aplicados nas bolsas de valores; decretação da Lei Complementar, mais conhecida como Lei de Responsabilidade Fiscal, no 101 de 2000, em que se estabeleceu uma hierarquia nos gastos públicos colocando o direito dos credores financeiros em grau de hierarquia superior à alocação de recursos com fins distributivos das políticas de renda e políticas públicas de modo geral; a reforma do setor previdenciário privado. (PAULANI, 2008)

Todas essas reformas estão, no plano político, amplamente amparadas pelo Plano Diretor de Reformas do Aparelho do Estado (BRASIL, 1995). É esse documento que passa a orientar todo o ordenamento jurídico relacionado à CT\&I a partir da racionalidade de um novo Estado reformado, induzindo efetivas mudanças na universidade pública requeridas pelo modelo de gestão econômica acima indicado. Nas universidades públicas, essas mudanças foram a passos largos tomando forma ao longo das últimas duas décadas, por meio de alterações legislativas ${ }^{2}$, publicação de Planos, conferências e novas diretrizes para a política industrial.

A inclusão das universidades e centros de pesquisas num chamado terceiro setor do Estado, ou no Núcleo de serviços não exclusivos do Estado, no âmbito do PDRE, passa a operar significativa mudança cultural, possibilitando novas relações da universidade com o Estado, sobretudo, no que diz respeito a seu financiamento direto, à contratação dos servidores, na relação dos seus professores com suas pesquisas e com os conhecimentos produzidos, dando feição a à instituição.

Nesse sentido, demonstra-se que a reforma do Estado está orientada por uma nova gestão do fundo público em favor do capital, sob a forma de investimentos infraestruturais, pela entrega de um nicho de mercado rentável com as vendas do patrimônio público na forma de empresas estatais, com a reforma

2 Podemos destacar como principais alterações legislativas: a Lei de Inovação Tecnológica no 10.973/2004 e conhecida como "Lei do Bem" no 11.196/2005, além da criação dos fundos setoriais, a partir de 1997. 
previdenciária, ao retirar o Estado do processo produtivo direto e a reforma universitária com duas amplas funções: certificação em massa e empresariamento do conhecimento. (SILVA JÚNIOR; KATO; FERREIRA, 2012)

De acordo Silva Júnior et al. (2012, p. 121),

\begin{abstract}
A ortodoxia que iria orientar todo o processo de reforma, e que de fato hoje vemos realizada, não foi escondida de ninguém que estivesse um pouco atento ao pronunciamento de FHC. "Tenho repetido à exaustão, mas não custa insistir: isto não significa que a ação do Estado deixe de ser relevante para o desenvolvimento econômico. Ela continuará sendo fundamental, mas mudando de natureza". [...]. A identidade das instituições universitárias estatais públicas deveria submeter-se à assertiva de FHC de que 'em vez de substituir o mercado, trata-se, portanto, de garantir a eficiência do mercado como princípio geral de regulação'. Para a realização do novo modelo de desenvolvimento, segundo Cardoso, a infraestrutura econômica e social constituía-se em ponto fundamental. [...].
\end{abstract}

Destaca-se o papel da educação para o novo modelo de desenvolvimento econômico adotado. A educação nos mais diversos níveis e modalidades passa a cumprir papel essencial na produção real de valor.

\footnotetext{
Aqui, portanto, a educação brasileira deveria, em seus níveis e modalidades, ser reformada. a Educação Básica e profissional deveria prover um incremento qualitativo e quantitativo na força de trabalho e a necessidade de exportação de produtos com alto valor agregado exigiria a produção de tecnologia e inovação, e, para isso, a demanda inequívoca de uma reforma educacional voltada para o trabalho e de natureza pragmática se punha como solução. (SILVA JÚNIOR et al., 2012, p. 121).
}

Nesse aspecto, as reformas educacionais foram sendo processadas com destaque para as mudanças na educação universitária: novas políticas de avaliação, sobretudo, de avaliação em nível pós-graduado capitaneado pela agência CAPES; expansão de vagas nas universidades públicas pelas mais variadas modalidades: REUNI, em 2007, Universidade Aberta do Brasil- UAB, em 2006; a produção de planos específicos de educação como os Planos Nacionais de Pós-Graduação, que passam a orientar, juntamente com a Política Industrial Tecnológica e de Comércio Exterior e o PAC da Ciência e Tecnologia, a formação e mobilidade internacional dos estudantes e professores pelo fomento de bolsas de estudos, estágios acadêmicos e participação em eventos internacionais, a criação de novos cursos, a produção do conhecimento, o financiamento de pesquisas e as regras de avaliação.

Há uma relação cada vez mais estreita entre a esfera educacional e a esfera econômica em face da opção de desenvolvimento produtivo e financeiro do país, onde a política econômica passa a ser a grande indutora das políticas públicas 
educacionais. É sob essa nova estrutura que a universidade estatal pública, como espaço de realização do fundo público, passa a ser considerada a "espinha dorsal" do desenvolvimento produtivo e financeiro do país, atribuindo-se às atividades dessa instituição grande peso social e econômico.

\section{PNPG 2011-2020: A ATUAL PROPOSTA DE FINANCIAMENTO PARA PÓS-GRADUAÇÃO NO BRASIL}

Oficialmente, o Plano Nacional de Pós-Graduação (PNPG) 2011-2020 cumpre o objetivo de definir novas diretrizes, estratégias e metas com vistas ao desenvolvimento da pós-graduação e pesquisa no Brasil para o próximo decênio. Alguns eixos são destacados como centrais no âmbito deste documento: a expansão do Sistema Nacional de Pós-Graduação; a criação de uma agenda nacional de pesquisas; o papel de indução da CAPES e do CNPq; o aperfeiçoamento da avaliação; o apoio aos demais níveis de ensino e a formação de recursos humanos para empresas.

Quando analisados os antecedentes do PNPG 2011-2020, nota-se que há uma indução histórica, de base econômica, expressa nos planos anteriores, que corroboram a hipótese apresentada por Silva Junior e Kato (2016), de que há uma relação direta entre a condução política de nosso recém Sistema Nacional de Pós-graduação e nosso modelo de desenvolvimento econômico, que funcionaliza o papel da universidade e do conhecimento ali produzido para a reprodução ampliada do capital.

$\mathrm{Na}$ leitura atenta do atual PNPG, identifica-se, na introdução do documento, a importância de se garantirem as condições para o desenvolvimento de pesquisas acadêmicas, assegurando autonomia cientifica às instituições "com largas margens de independência das urgências e imediatismos postos seja pelo mercado, seja pela sociedade". Entretanto, afirma-se que o ineditismo do plano consiste em que "a afirmação da autonomia deve ser acompanhada de uma maior sensibilidade para com formas renovadas de interação com a sociedade" (BRASIL, 2010, p. 8).

Ou seja, a estrutura pós-graduada brasileira, que produz pesquisa/ conhecimento, é estratégica para o desenvolvimento produtivo brasileiro:

Aqui são várias as frentes de trabalho. Temos em mente duas em especial: 1. A criação de instrumentos que possibilitem a atenuação da distância entre a produção do conhecimento e a apropriação pública e 2. A participação da universidade enquanto instituição na formulação e/ou implementação nas metas nacionais de desenvolvimento. [...] diz respeito às possibilidades de incorporar o conhecimento 
disponível na universidade para a resolução de grandes problemas de natureza geopolítica presentes no cenário nacional e que sejam portadores claro de futuro. (BRASIL, 2010, p. 9).

Tal constatação foi comprovada por Kato (2013) em sua tese, que analisou a nova política de financiamento de pesquisas do Conselho Nacional de Desenvolvimento Científico e Tecnológico (CNPq) e as possíveis mediações entre a política econômica adotada no Brasil a partir da década de 1990 e o papel que essa agência cumpre na agenda de políticas públicas produtivas do país.

O estudo de Kato (2013) indicou que a política econômica brasileira adotada a partir da década de 1990 explica as ações adotadas pelo CNPq a partir dos anos 2000. Ao ingressar na predominância financeira, o país teve que implementar uma série de reformas estruturais para se tornar atrativo aos investimentos produtivos e financeiros.

A prioridade central do país nessa nova adesão ao capital financeiro passou a ser a preservação de garantias constitucionais aos credores. São esses os objetivos que vêm orientando, de acordo com Kato (2013), há quase duas décadas qualquer reforma econômica, política e educacional no país. No plano político, a reforma do Estado brasileiro anunciada no início da era FHC (1995-2002) foi a mais cabal tradução desse conjunto de medidas adotadas após o Plano Real. É ela quem passa a orientar todas as reformas nas instituições, com destaque para as mudanças nas práticas acadêmicas das universidades públicas e na produção de conhecimento.

Desse ponto de vista, orientado por uma nova agenda de crescimento do país, dado a conjuntura internacional e às alianças políticas com o empresariado nacional, Lula (2003-2010), ao assumir a presidência da República, optou pela manutenção da agenda ortodoxa de gestão da economia, mas intentou buscar alternativas de crescimento produtivo e de ampliação de investimentos em longo prazo. Seu projeto político iniciado em 2003 se expressou de modo mais cabal pela implementação de uma nova política industrial. (KATO, 2013)

Em relação a sua coleção de práticas de política econômica, Lula retomou a Política industrial Nacional e a Política de Desenvolvimento Produtivo (PITCE e PDP) com foco na inovação e na relação cooperativa entre Estado, universidades e mercado. Essas opções de sua política econômica produziram mudanças no paradigma de financiamento público de pesquisas do CNPq, expresso na publicação dos primeiros editais de apoio à pesquisa científica e tecnológica, e em novo aparato jurídico-legal, como a Lei de Inovação Tecnológica (Lei no 10.973/2004) e a Lei do Bem (Lei no 11.196/2005).

Além disso, esse novo desenho da política de financiamento, passa a orientar-se pela Política Industrial, Tecnológica e de Comércio Exterior (PITCE) 
que se baseia: no foco na inovação, incentivo à formação de um pesquisadorcriador, ênfase nas pesquisas de natureza aplicada em detrimento das pesquisas de natureza acadêmica, forte subvenção pública orientada para o crescimento econômico, visando a posicionar o Brasil em plataforma de valorização financeira. (KATO, 2013)

Tais orientações, portanto, também se apresentam explicitamente na análise do atual PNPG, visto haver uma linha de continuidade política de Lula da Silva com sua sucessora, que manteve a agenda econômica e produtiva do país. $\mathrm{Na}$ leitura do PNPG em vigor, constatou-se sob várias perspectivas: a criação de uma agenda nacional de pesquisas e a formação de pesquisadores com vistas a integrar a produção de conhecimento e sua apropriação pelas empresas; forte papel de indução das agências CAPES e CNPq na produção de novos conhecimentos e na formação de pesquisadores e de cursos de pós-graduação voltados para áreas estratégicas da política industrial (engenharias, tecnológicas, química, fármaco, etc.) via editais.

Em relação ao ‘Financiamento da Pós-Graduação’ o V PNPG aborda a questão afirmando que a referência de financiamento se dá predominantemente por duas esferas distintas: "Os dispêndios do setor federal, com foco nas duas maiores instituições de fomento, CAPES e CNPq, e os dos setores estaduais nesse caso, as Fundações de Apoio à Pesquisa (FAP's)". Desse ponto de vista, parte da agenda nacional que cumpre a esse plano para o próximo decênio, estimularia a ampliação e diversificação de financiamento, pois segundo dados nacionais a maior estrutura de financiamento no Brasil para as atividades de pósgraduação advém dos recursos públicos federais, na figura da Coordenação de Aperfeiçoamento de Pessoal de nível Superior (CAPES) e do CNPq e, estaduais, por meio das FAP's (Fundações de Amparo à Pesquisa), na promoção direta do financiamento de pesquisas por via de editais. De outro lado, o financiamento da pós-graduação se realiza pelo Ministério da Educação (MEC), mediante o pagamento do salário de professores com dedicação exclusiva, doutores e com tempo integral para se dedicarem às pesquisas.

Assim, consolida-se a política de indução pela via de editais, que buscam estimular a produção de conhecimento e a formação de pesquisadores em áreas consideradas estratégicas para a Política Industrial, Tecnológica e de Comércio Exterior e a Política de Desenvolvimento Produtivo.

No âmbito do setor privado, o financiamento da pós-graduação dar-se-á pela via de concorrência aos editais de apoio à pesquisa das agências de fomento e, ainda, por programas específicos que objetivam estimular o suporte financeiro a esses programas, a exemplo do Programa de suporte à Pós-graduação das 
Instituições de ensino particulares (PROSUP), oferecido via editais pela CAPES, que incluem pagamento de bolsas aos alunos e taxas escolares.

Há a indicação no âmbito do PNPD de que haja ampliação e correções desse programa, sobretudo em busca de estímulo, como na ampliação de oferta de Bolsas de Produtividade para a dedicação integral dos professores a suas atividades:

\begin{abstract}
O setor privado carece, fundamentalmente, de pessoal docente de alto nível em tempo integral. Ocorre, no entanto que dificilmente esses podem ser contratados com os recursos provenientes das taxas escolares e auxílio tese em cursos com pelo menos o conceito 3. [...] A grande dificuldade das instituições particulares, a retenção de professores doutores em dedicação exclusiva, não está sendo resolvida pelo PROSUP e nem por outros mecanismos, tais como a bolsa de produtividade do CNPq. (BRASIL, 2010, p. 304).
\end{abstract}

De outro lado, há a indicação para criação de novas linhas de credito para induzir a expansão e o financiamento da pós-graduação. Tal indicação apresentase na meta 14 do atual PNE, que, na sua estratégia 14.3, indica "Expandir o financiamento estudantil por meio do Fies à pós-graduação stricto sensu". Nesse sentido, "A adoção de novas modalidades de crédito subsidiado para estudos de mestrado e doutorado, bem como outras formas de financiamento às instituições universitárias e de pesquisa particulares que mantenham programas de excelência precisam ser consideradas com urgência”. (Idem, p. 280)

Outros dois pontos em destaque no âmbito do PNPG merecem especial atenção para os fins deste trabalho. $O$ primeiro diz respeito à recomendação de reformas no arcabouço legal, para que as agências de fomento federais e estaduais tenham maior flexibilidade no uso dos recursos destinados à Ciência, tecnologia e Inovação (CT\&I), sobretudo, no âmbito dos órgãos de prestação de contas como Tribunal de Contas da União (TCU), Controladoria Geral da União (CGU), Advocacia-Geral da União (AGU) e Ministério Público da União (MPU):

\footnotetext{
O pesquisador pode e deve, além de promover a inovação, participar da inserção do resultado de sua pesquisa no mercado produtivo. Esse fato já foi registrado na proposta MEC/MPOG, que cuida da flexibilização da dedicação exclusiva, e em outros estudos. Essa iniciativa oficializa a prestação de serviços que não tenham qualquer caráter acadêmico; resolve os problemas apresentados pelo TCU, relativos à participação do pesquisador em empresa, incluindo-se a possibilidade de dirigentes das IFES ocuparem simultaneamente cargos de direção nas administrações das fundações de apoio. Um primeiro passo nesse sentido seria estimular a criação de uma carreira específica para esses cientistas, vinculada a um órgão federal, como por exemplo o Ministério da Ciência e Tecnologia (MCT). Isso possibilitaria um maior aproveitamento do conhecimento desses pesquisadores, que poderiam ser envolvidos em estudos compartilhados entre universidades, indústrias ou outros órgãos públicos. (BRASIL, 2010, p. 279).
} 
A eliminação dos entraves burocráticos que impedem as atividades de assessoria e consultoria de pesquisadores do Regime Jurídico Único às empresas públicas e privadas e, ainda, a flexibilização das amarras que cerceiam a contratação, pelo sistema público, de experts nacionais e internacionais estão contempladas em grande parte pela Lei no 13.243/2016, ou novo Código Nacional de Ciência, Tecnologia e Inovação, indicando que o projeto nacional de Ciência, Tecnologia e Inovação (CT\&I) em curso no país alcança, sobretudo, o âmbito da produção de conhecimento, por meio da atuação da pós-graduação, com metas de Estado cada vez mais 'ambiciosas' em relação à expansão, à diversidade no financiamento (público e privado) e à internacionalização, dispostas não somente no marco regulatório especifico (o PNPG), mas no planejamento do sistema mais ampliado, da Ciência e Tecnologia e Plano Nacional de Educação, conforme exposto no item seguir.

\section{O NOVO PLANO NACIONAL DE EDUCAÇÃO E AS DIRETRIZES PARA A PÓS-GRADUAÇÃO}

O Plano Nacional de Educação em vigor, implementado pela Lei $n^{\circ}$ 13.005, de 25 de junho de 2014, com vigência para os próximos dez anos, apresenta vinte metas para educação a serem cumpridas até o ano de 2024.

Em relação às diretrizes para a pós-graduação, apresenta-se a Meta 14, que dispõe sobre as estratégias para sua expansão e financiamento: "elevar gradualmente o número de matrículas na pós-graduação stricto sensu, de modo a atingir a titulação anual de 60.000 (sessenta mil) mestres e 25.000 (vinte e cinco mil) doutores", cujos desdobramentos se ampliam em 14 estratégias:

14.1) expandir o financiamento da pós-graduação stricto sensu por meio das agências oficiais de fomento; 14.2) estimular a integração e a atuação articulada entre a Coordenação de Aperfeiçoamento de Pessoal de Nível Superior (CAPES) e as agências estaduais de fomento à pesquisa; 14.3) expandir o financiamento estudantil por meio do Fies à pós-graduação stricto sensu; 14.4) expandir a oferta de cursos de pós-graduação stricto sensu, utilizando inclusive metodologias, recursos e tecnologias de educação a distância; 14.5) implementar ações para reduzir as desigualdades étnico-raciais e regionais e para favorecer o acesso das populações do campo e das comunidades indígenas e quilombolas a programas de mestrado e doutorado; 14.6) ampliar a oferta de programas de pós-graduação stricto sensu, especialmente os de doutorado, nos campi novos abertos em decorrência dos programas de expansão e interiorização das instituições superiores públicas; 14.7) manter e expandir programa de acervo digital de referências bibliográficas para os cursos de pós-graduação, assegurada a acessibilidade às pessoas com deficiência; 14.8) estimular a participação das mulheres nos cursos de pós-graduação stricto sensu, em particular aqueles ligados às áreas de Engenharia, Matemática, Física, Química, Informática e outros no campo das ciências; 14.9) consolidar programas, 
projetos e ações que objetivem a internacionalização da pesquisa e da pós-graduação brasileiras, incentivando a atuação em rede e o fortalecimento de grupos de pesquisa; 14.10) promover o intercâmbio científico e tecnológico, nacional e internacional, entre as instituições de ensino, pesquisa e extensão; 14.11) ampliar o investimento em pesquisas com foco em desenvolvimento e estímulo à inovação, bem como incrementar a formação de recursos humanos para a inovação, de modo a buscar o aumento da competitividade das empresas de base tecnológica; 14.12) ampliar o investimento na formação de doutores de modo a atingir a proporção de 4 (quatro) doutores por 1.000 (mil) habitantes; 14.13) aumentar qualitativa e quantitativamente o desempenho científico e tecnológico do País e a competitividade internacional da pesquisa brasileira, ampliando a cooperação científica com empresas, Instituições de Educação Superior (IES) e demais Instituições Científicas e Tecnológicas (ICTs); 14.14) estimular a pesquisa científica e de inovação e promover a formação de recursos humanos que valorize a diversidade regional e a biodiversidade da região amazônica e do cerrado, bem como a gestão de recursos hídricos no semiárido para mitigação dos efeitos da seca e geração. (BRASIL, 2014, p. 12).

Tal como previsto no principal manifesto político da pós-graduação já apresentado no item anterior, as estratégias vislumbradas no PNE mantêm linha de continuidade com as políticas apresentadas no âmbito do PNPG, que se caracterizam pela indução e regulação ao uso do fundo público via agências de fomento (CAPES e CNPq), Fundações estaduais de amparo à pesquisa, para a expansão da pós-graduação, além do financiamento para as Instituições de Ensino Superior privadas com previsão de incremento ao Programa de Financiamento Estudantil (FIES) estendido agora à pós-graduação stricto sensu, o que pode conferir à este nível educacional um papel central na produção de um conhecimento orientado pela demanda da predominância financeira e de mercado.

$\mathrm{Na}$ última década, os elementos oferecidos pelo histórico jurídiconormativo mostram um processo em transição, na qual a CAPES assume o papel de incentivar e conduzir um pretenso desenvolvimento econômico e social do país, justamente pautada na expansão da pós-graduação, que, de fato, será consolidada quando a transferência de tecnologia e recursos assumir ainda maior importância na vida institucional de pesquisadores, programas de pós-graduação e empresas e que favoreçam a redução das discrepâncias existentes na pesquisa e na pós-graduação entre as regiões do país.

Ações nessa direção já se colocam na prática, seja por regulações como a Lei Lei $\mathrm{n}^{\mathrm{o}}$ 10.973, de 2 de dezembro de 2004, de Inovação Tecnológica, que "estabelece medidas de incentivo à inovação e à pesquisa científica e tecnológica no ambiente produtivo, com vistas à capacitação e ao alcance da autonomia tecnológica e ao desenvolvimento industrial do País" (BRASIL, 2004, p. 1); e a Lei do Bem, Lei n ${ }^{\circ} 11.196$, de 21 de novembro de 2005, que criou a concessão 
de incentivos fiscais às pessoas jurídicas que realizarem pesquisa, cuja essência se firma pelo desenvolvimento de inovação tecnológica que orienta demandas do capital produtivo, ou ainda, no último PNPG.

O V PNPG, com vigência de 2011 a 2020, parece concretizar e fortalecer uma política que se consolida há quase duas décadas, numa tentativa de mudar a cultura da educação superior, especialmente pública, a qual a produção do conhecimento e a formação de novos pesquisadores ficam comprometidos ao desempenho da produção, principalmente, pelo "Aumento do valor agregado de nossos produtos e a conquista competitiva de novos mercados no mundo globalizado." (BRASIL, 2010, p. 37 e 255). Nesse contexto, a questão do financiamento da pós-graduação se torna referência, pois, para quintuplicar o número atual de titulados - que em 2013 conferia 45.067 mestres e 15.287 doutores (GEOCAPES, 2014) - será necessário investigar as estratégias para essa façanha de tamanho porte.

O Brasil buscou aprimorar os mecanismos de fomento à pós-graduação, à Ciência, à Tecnologia e Inovação (CT\&I), especialmente no governo Lula da Silva, com renovação do papel da regulação e do fomento à pesquisa, em especial por agências executoras de um pacto nacional de CT\&I, como a Coordenação de Aperfeiçoamento de Pessoal de Nível Superior (CAPES), agencia de regulação e fomento que subsidia o Ministério da Educação no âmbito da pós-graduação, de cujo orçamento se observa a expansão e diversificação na Tabela 1, a seguir: 
Tabela 1 - CAPES - Total do Orçamento por itens de ação, valor executado, 2004-2015, em $\mathbf{R} \$ 1.000,00$

\begin{tabular}{|c|c|c|c|c|c|c|c|c|c|}
\hline AÇÃO & 2004 & 2006 & 2008 & 2010 & 2012 & 2014 & 2015 & $\begin{array}{c}\Delta \% \\
2004- \\
2015^{* *}\end{array}$ & $\begin{array}{c}\Delta \% \\
2014= \\
2015\end{array}$ \\
\hline $\begin{array}{c}\text { Bolsa de } \\
\text { Estudo }\end{array}$ & 953.330 & 1.056 .526 & 1.414 .598 & 2.255 .273 & 3.607 .730 & 5.323 .126 & 6.811 .795 & 614,5 & 28,0 \\
\hline País & 754.646 & 798.544 & 913.088 & 1.230 .482 & 1.985 .322 & 2.646 .816 & 2.251 .862 & 198,4 & $-14,9$ \\
\hline Exterior & 176.639 & 197.290 & 141.867 & 121.266 & 831.595 & 162.219 & 138.233 & $-21,7$ & $-14,8$ \\
\hline $\begin{array}{l}\text { Política } \\
\text { Industrial }\end{array}$ & - & 59.420 & 68.819 & 126.810 & .. & .. & .. & $\ldots$ & $\ldots$ \\
\hline $\begin{array}{c}\text { Novas } \\
\text { Fronteiras/ } \\
\text { CsF* }^{*}\end{array}$ & - & - & 24.243 & 29.485 & .. & 1.588 .911 & 3.338.240 & \#REF! & 110,1 \\
\hline $\begin{array}{l}\text { Cooperação } \\
\text { Internacional }\end{array}$ & 22.043 & 1.271 & 83.748 & 125.894 & .. & .. & .. & $\ldots$ & $\ldots$ \\
\hline $\begin{array}{l}\text { Coop. } \\
\text { Inter. Para } \\
\text { Educação } \\
\text { Básica }\end{array}$ & - & - & - & 4.412 & .. & .. & & $\ldots$ & $\ldots$ \\
\hline $\begin{array}{c}\text { Plano } \\
\text { Nacional } \\
\text { de Pós- } \\
\text { Graduação }\end{array}$ & - & - & 18.299 & 97.686 & .. & .. & & $\ldots$ & $\ldots$ \\
\hline $\begin{array}{l}\text { Iniciação à } \\
\text { Docêncial } \\
\text { PIBID }\end{array}$ & - & - & - & 117.462 & .. & .. & & $\ldots$ & $\ldots$ \\
\hline $\begin{array}{c}\text { Educação } \\
\text { Básica (UAB/ } \\
\text { PARFOR) }\end{array}$ & - & - & 164.531 & 401.772 & 790.812 & 925.178 & 1.083 .458 & 462,3 & 17,1 \\
\hline Fomento & 30.862 & 51.702 & 361.655 & 354.608 & 968.688 & 443.033 & 138.008 & 1335,5 & $-68,8$ \\
\hline $\begin{array}{c}\text { Pós- } \\
\text { Graduação }\end{array}$ & 30.862 & 51.702 & 143.402 & 187.393 & 605.515 & 166.177 & 80.498 & 438,5 & $-51,6$ \\
\hline UAB & - & - & 218.252 & 108.746 & .. & .. & .. & $\ldots$ & $\ldots$ \\
\hline $\begin{array}{l}\text { Educação } \\
\text { Básica }\end{array}$ & $\ldots$ & $\ldots$ & $\ldots$ & 58.467 & 363.172 & 276.856 & 57.510 & $\ldots$ & $\ldots$ \\
\hline $\begin{array}{c}\text { Portal } \\
\text { Periódicos }\end{array}$ & 93.540 & 138.181 & 162.445 & 171.470 & 227.003 & 193.533 & 291.310 & 106,9 & 50,5 \\
\hline Avaliação & 13.180 & 10.335 & 11.245 & 13.461 & 13.762 & 12.446 & 11.890 & $-5,6$ & $-4,5$ \\
\hline $\begin{array}{l}\text { VALOR } \\
\text { TOTAL }\end{array}$ & 1.090 .912 & 1.256 .744 & 1.949 .943 & 2.794 .812 & 4.817 .183 & 5.972 .138 & 7.253 .003 & 447,4 & 21,4 \\
\hline
\end{tabular}

Fonte: CAPES.

* Confere ao Programa Ciência Sem Fronteiras.

** O valor da evolução do investimento executado na Educação básica corresponde ao período de 2008 a 2015, quando decorreu seu inicio.

A tabela 1, demonstra a relação da Capes com o financiamento dos Programas de Pós-Graduação; os dados evidenciam um acréscimo de 833,6\% no 
total do orçamento, no período de 2004 a 2015, especialmente voltado à expansão das 'bolsas de estudo', com destaque ao Programa Novas Fronteiras. Em 2010, ainda como Programa Novas Fronteiras, representava 1,3\% do orçamento reservado às bolsas, na formatação do Programa Ciências sem Fronteiras - CsF. A partir de 2010, os dados passam a mudar. O programa toma tal importância que, no orçamento de 2014, chega a 30\% e, em 2015, toma cerca de 50\% dos recursos da Agência. Observa-se, com isso, que a política de financiamento da CAPES estabeleceu o programa CsF como prioritário na destinação de bolsas, chegando, em 2015, a receber 3,1 bilhões de reais enquanto todas as demais bolsas de pós-graduação do país receberam 2,1 bilhões de reais no mesmo ano.

Vale destacar, que, embora o PNPG tenha se voltado para a expansão da titulação, a expansão do orçamento da Capes, como apresentado, vem favorecendo a expansão da graduação e do doutoramento, com bolsas em áreas prioritárias, que, no contexto de crise, ainda apresentam futuro incerto. No entanto, a formação de novos doutores remete não somente às estratégias de expansão, mas ao desenvolvimento produtivo e tecnológico do país:

\footnotetext{
A formação de doutores tem sido considerada de extrema importância na produção e transmissão do conhecimento e é considerada um indicador do tipo de sociedade moderna que se deseja construir. [...] em 2008, existiam 132 mil doutores no Brasil, correspondentes a $0,07 \%$ da nossa população. Para alcançar as proporções dos países desenvolvidos seria necessário, no mínimo, multiplicar esse número por cinco vezes. (BRASIL, 2010, p. 255).
}

Assim, posta a necessidade de multiplicação dos novos doutores, na tese intitulada $O$ trabalho do Professor jovem-doutor na pós-graduação: produção de conbecimento e discurso do professor (FERREIRA, 2015) destacou-se que a vivência na formação doutoral numa lógica de avaliação por produção científica, sob novos critérios de avaliação da Capes a partir de 1998, contribuiu para a forma naturalizada com que passou a ser encarado o cotidiano do trabalho intensificado, numa compressão dp espaço-tempo de elaboração do conhecimento, que refletiu, por sua vez, na própria forma de orientar seus alunos de pós-graduação, "Mas, sobretudo, o contexto foi fundamental para se identificar um perfil altamente produtivo e empreendedores de projetos e financiamentos". Nesse sentido, acrescenta-se que “o fetiche do trabalho docente está agregado ao 'produto', no caso, as produções científicas das quais decorrem os indicadores, [e] a qualificação da produção [...]", e tudo mais que se relaciona com a produção e o financiamento desta e, por isso, o papel fundamental das Agências de fomento e FAP's para a manutenção dessa lógica produtivista.

Este novo lugar do CNPq e da Capes, conferiu-lhes peso estratégico na construção de um pacto nacional entre universidade-Estado-mercado (capital 
financeiro), atuando precipuamente na formação de recursos humanos pelo fomento das mais variadas modalidades e níveis de bolsas aliado a um novo formato de financiamento que passou a induzir a produção de conhecimento nas universidades.

\section{CONSIDERAÇÕES FINAIS}

Tal como se expôs na introdução deste artigo, quando se apresentou a tramitação da Proposta de Emenda à Constituição (PEC) no 395/2014 e a aprovação do novo marco regulatório para a ciência, tecnologia e inovação representado aqui pela Lei no 13.243/2016, o Brasil vem ampliando seu escopo de reformas estruturais, que traduzem a atualização de um projeto nacional que se institucionaliza, a conta-gotas, desde a década de 1990, em direção à mercantilização da educação superior, especialmente da pós-graduação, como principal agente de produção de conhecimento e inovação.

Quando aqui se analisou tal adaptabilidade pela via da Educação Superior, especificamente da pós-graduação, verificou-se a necessidade exposta pelo atual PNPG em relação a ampliação e diversificação de financiamento, com maior abertura ao investimento privado, e expansão na atuação das agências de fomento e FAP's; consequentemente, entende-se, o direcionamento a pesquisas mais voltadas ao setor produtivo. Do mesmo modo, observa-se a concretização sob a forma de metas bem expostas no atual PNE, o qual prevê estratégias que passam tanto pela expansão pública de financiamento, quanto pelo meio privadomercantil, via PROSUP ou, ainda, pela implantação do FIES para a pós-graduação stricto sensu, justamente para alcançar a expansão do número de doutores.

Ao contrário da aparência propagandeada pelo discurso neoliberal, que, ideologicamente, baseia-se na desnecessidade do público (OLIVEIRA, 1999) no financiamento e na expansão da educação, ao se proceder à análise desses planos, a coleção de práticas políticas em vigor nos indica o contrário: é o fundo público sob a forma de orçamento federal e estadual via agências de fomento como CAPES, CNPq e Fundações de Apoio estaduais à pesquisa que direciona um ordenamento jurídico competente e flexível que vem colocando em movimento a mercantilização das atividades da universidade estatal pública.

O projeto nacional de expansão e financiamento, por meio de agências de fomento, como Capes e CNPq, atende às exigências da adaptabilidade, sobretudo regulatória, por meio de Planos Nacionais citados, PNPG e PNE, que referenciam um pacto social mundializado que exige a presença do fundo público em suas políticas econômicas e no desenvolvimento produtivo, nos quais a ciência se engaja ao mercado na construção do novo pacto social, com unidade planetária, 
que passa pela mudança na pós-graduação, do papel do professor-pesquisador, no financiamento das pesquisas e pela contradição entre as esferas indissociáveis e antagônicas - pública e privada.

\section{REFERÊNCIAS}

SINDICATO NACIONAL DOS DOCENTES DAS INSTITUIÇÕES DE ENSINO SUPERIOR. Ameaça à gratuidade nas IES públicas, PEC 395 vai à votação em segundo turno. Disponível em: $<$ http//andes-ufsc.org. br/ameaca-a-gratuidade-nas-ies-publicas-pec-395-vai-a-votacao-em-segundoturno/>. Acesso em: 18 de ago, 2016.

BRASIL. Constituição da República Federativa do Brasil, de 5 de outubro de 1988.

Diário Oficial [da] República Federativa do Brasil, Brasília, DF, 5 out. 1988. Disponível em: <http://www2.camara.leg.br/atividade-legislativa/legislacao/ Constituicoes_Brasileiras/constituicao1988.html>. Acesso em: 1 maio 2016.

BRASIL. Lei no 13.243, de 11 de janeiro de 2016. Dispõe sobre os estímulos ao desenvolvimento científico à pesquisa, à capacitação científica e tecnológica e à inovação. Diário Oficial [da] República Federativa do Brasil, Brasilia, DF, 12 jan. 2016. Disponível em: <http://www.planalto.gov.br/ccivil_03/_ato20152018/2016/lei/113243.htm>. Acesso em: 04 jun. 2016.

Lei no 13.005, de 25 de junho de 2014. Aprova o Plano Nacional de Educação - PNE e dá outras providências. Diário Oficial [da] República Federativa do Brasil, Brasília, DF, 26 jun. 2014. Disponível em: <http://www. planalto.gov.br/ccivil_03/_ato2011-2014/2014/lei/113005.htm>. Acesso em: 18 ago. 2016.

Ministério da Educação. Coordenação de Aperfeiçoamento de Pessoal de Nível Superior. Plano Nacional de Pós-graduação-PNPG 2011-2020. Brasília, DF: CAPES, 2010.

BRASIL. Lei no 11.196, de 21 de novembro de 2005. Institui o Regime Especial de Tributação para a Plataforma de Exportação de Serviços de Tecnologia da Informação - REPES, o Regime Especial de Aquisição de Bens de Capital para Empresas Exportadoras - RECAP e o Programa de Inclusão Digital; dispõe sobre incentivos fiscais para a inovação tecnológica; altera o Decreto-Lei no 288, de 28 de fevereiro de 1967, o Decreto no 70.235, de 6 de março de 1972, o Decreto-Lei 
no 2.287, de 23 de julho de 1986, as Leis nos 4.502, de 30 de novembro de 1964, 8.212, de 24 de julho de 1991, 8.245, de 18 de outubro de 1991, 8.387, de 30 de dezembro de 1991, 8.666, de 21 de junho de 1993, 8.981, de 20 de janeiro de 1995, 8.987, de 13 de fevereiro de 1995, 8.989, de 24 de fevereiro de 1995, 9.249, de 26 de dezembro de 1995, 9.250, de 26 de dezembro de 1995, 9.311, de 24 de outubro de 1996, 9.317, de 5 de dezembro de 1996, 9.430, de 27 de dezembro de 1996, 9.718, de 27 de novembro de 1998, 10.336, de 19 de dezembro de 2001, 10.438, de 26 de abril de 2002, 10.485, de 3 de julho de 2002, 10.637, de 30 de dezembro de 2002, 10.755, de 3 de novembro de 2003, 10.833, de 29 de dezembro de 2003, 10.865, de 30 de abril de 2004, 10.925, de 23 de julho de 2004, 10.931, de 2 de agosto de 2004, 11.033, de 21 de dezembro de 2004, 11.051, de 29 de dezembro de 2004, 11.053, de 29 de dezembro de 2004, 11.101, de 9 de fevereiro de 2005, 11.128, de 28 de junho de 2005, e a Medida Provisória no 2.199-14, de 24 de agosto de 2001; revoga a Lei no 8.661, de 2 de junho de 1993, e dispositivos das Leis nos 8.668, de 25 de junho de 1993, 8.981, de 20 de janeiro de 1995, 10.637, de 30 de dezembro de 2002, 10.755, de 3 de novembro de 2003, 10.865, de 30 de abril de 2004, 10.931, de 2 de agosto de 2004, e da Medida Provisória no 2.158-35, de 24 de agosto de 2001; e dá outras providências. Diário Oficial [da] República Federativa do Brasil, Brasilia, DF, 22 nov. 2005. Disponível em: <https://www. planalto.gov.br/Ccivil_03/_Ato2004-2006/2005/Lei/L11196.htm>. Acesso em: 15 set. 2016.

. Lei no 10.973, de 02 de dezembro de 2004. Dispõe sobre incentivos à inovação e à pesquisa científica e tecnológica no ambiente produtivo e dá outras providências. Diário Oficial [da] República Federativa do Brasil, Brasília, DF, 03 dez. 2004. Disponível em: <http://www.planalto.gov.br/ccivil_03/_ato20042006/2004/lei/110.973.htm>. Acesso em: 18 ago. 2016.

Casa Civil. Diretrizes de Política Industrial, Tecnológica e de Comércio Exterior. Brasília, DF, 2003. Disponível em: <http://www.abdi.com. br/Paginas/politica_industrial.aspx >. Acesso em: 18 ago. 2016.

Ministério da Administração Federal e Reforma do Estado. Plano Diretor da Reforma do Aparelho do Estado. Brasilia, DF, 1995.

CHAUÍ, Marilena. Ideologia neoliberal e universidade. In: OLIVEIRA, Francisco de; PAOLI, Maria Celia (Orgs.). Os sentidos da democracia: políticas do dissenso e hegemonia global. 2. ed. Petrópolis: Vozes, 1999. p. 27-51. 
CHESNAIS, François. A mundialização do capital. São Paulo: Xamã, 1996.

FERREIRA, Luciana Rodrigues. O trabalho do Professor jovem-doutor na pós-graduação: produção de conhecimento e discurso do professor. 2015. 204 f. Tese (Doutorado em Educação). Universidade Federal de São Carlos, SP, 2015.

GEOCAPES. Distribuição de Programas de Pós-graduação no Brasil 2004 e 2014. Visão Analítica. Planilha do Excel. 2014. Disponível em: <http://geocapes. capes.gov.br/geocapes2/>. Acesso em: 27 mar. 2016.

KATO, Fabíola. A nova política de financiamento de pesquisas: reforma no Estado e no novo papel do CNPq. 2013. 179 f. Tese (Doutorado em Educação) Universidade Federal de São Carlos, São Carlos-SP, 2013.

OLIVEIRA, Francisco. Privatização do público, destituição da fala e anulação da política: o totalitarismo neoliberal. In: OLIVEIRA, Francisco de; PAOLI, Maria Celia (orgs.). Os sentidos da democracia: políticas do dissenso e hegemonia

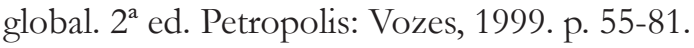

PAULANI, Leda. Brasil Delivery. São Paulo: Boitempo, 2008.

ROUSSEFF, Dilma. Discurso da Presidenta da República, Dilma Rousseff. [durante a cerimônia de sanção do marco legal da ciência, tecnologia e inovação e lançamento da chamada universal] - Brasília. Disponível em: <http://www2. planalto.gov.br/acompanhe-o-planalto/discursos/discursos-da-presidenta/ discurso-da-presidenta-da-republica-dilma-rousseff-durante-a-cerimonia-desancao-do-marco-legal-da-ciencia-tecnologia-e-inovacao-e-lancamento-dachamada-universal-brasilia-df>. Acesso em: 18 mar. 2016.

SILVA JÚNIOR, João dos Reis; KATO, Fabiola Bouth Grello. A política de internacionalização da educação superior no Plano Nacional de Pós-graduação (2011-2020). Revista Internacional de Educação Superior, Campinas, v. 2, n. 1, p. 138-151, jan./abr. 2016. Disponível em: < http//ojs.fe.unicamp.br/ged/ RIESup>. Acesso em: 01 ago. 2016.

SILVA JÚNIOR, João dos Reis; PIMENTA, Alan Victor; KATO, Fabíola Bouth Grello; FERREIRA, Luciana Rodrigues; ANELLI JÚNIOR, Luiz Carlos. Os 
significados do trabalho do professor pesquisador na universidade estatal pública mercantilizada. Relatório Científico Final. (Processo FAPESP n ${ }^{\circ}$ 2009/08661-0). set. 2012.

SILVA JÚNIOR, João dos Reis; KATO, Fabiola Bouth Grello; FERREIRA, Luciana Rodrigues. Universidade pública brasileira: mercantilização do conhecimento e certificação em massa. In: ARELARO, Lisete; FRANCA, Gilberto Cunha; MENDES, Maira Tavares (orgs.). Às portas da universidade: alternativas de acesso ao ensino superior. São Paulo: Xamã, 2012. p. 33-53.

FABÍOLA BOUTH GRELLO KATO é doutora e Mestre em Educação pela Universidade Federal de São Carlos. Professora do Programa de Pós-graduação em Educação da Universidade Federal do Pará na linha de pesquisa de Política Educacional. Pesquisadora da Rede Universitas/Br, participando do OBEDUC "Políticas da Expansão da Educação Superior no Brasil". E-mail: fabiola_kato@ hotmail.com.

LUCIANA RODRIGUES FERREIRA é doutora em Educação pela Universidade Federal de São Carlos, na linha de Estado, politica e Formação Humana. Mestre em educação pela Universidade Federal do Pará. Professora do Programa de PósGraduação em Administração da Universidade da Amazônia (Unama). Pesquisadora da Rede Universitas/Br, participando do OBEDUC "Políticas da Expansão da Educação Superior no Brasil”. E-mail: lucianarofer@gmail.com.

Recebido em setembro de 2016

Aprovado em outubro de 2016 